\title{
MODELAGEM DE UM EQUIPAMENTO PARA DESTILAÇÃO DE VINHO DELEVEDURADO
}

\section{ARTIGO ORIGINAL}

SILVEIRA, Kelly da Mota ${ }^{1}$, ARCHANJO, Elisabeth da Vitória ${ }^{2}$, SANTOS, Alexsander Saves dos ${ }^{3}$

SILVEIRA, Kelly da Mota. ARCHANJO, Elisabeth da Vitória. SANTOS, Alexsander Saves dos. Modelagem de um equipamento para destilação de vinho delevedurado. Revista Científica Multidisciplinar Núcleo do Conhecimento. Ano 06, Ed. 06, Vol. 14, pp. 143-156. Junho de 2021. ISSN: 2448-0959, Link de acesso: https://www.nucleodoconhecimento.com.br/quimica/vinho-delevedurado,

DOI: 10.32749/nucleodoconhecimento.com.br/quimica/vinho-delevedurado

\section{RESUMO}

O projeto realizado teve como principal objetivo desenvolver um destilador simples para o vinho delevedurado, enfatizando sua importância no meio industrial. $\mathrm{O}$ artigo mostra o desenvolvimento do destilador, desde a fundamentação teórica ao projeto físico. Para avaliar a eficiência e qualidade do produto final, incluíram-se testes para encontrar o Grau GL, análises do vinho delevedurado utilizado e do álcool destilado. Utilizando a destilação simples para obtenção de máxima separação, concluiu-se que o equipamento desenvolvido foi eficiente mesmo com a parada na fermentação, atendendo às especificações para um produto final com ${ }^{\circ} \mathrm{GL}$ médio de 58,3 .

Palavras-chave: Álcool, destilador, vinho.

\footnotetext{
${ }^{1}$ Graduando em Engenharia Química.

${ }^{2}$ Graduando em Engenharia Química.

${ }^{3}$ Orientador. Mestrado em Ciências Ambientais.
}

RC: 89567

Disponível em: https://www.nucleodoconhecimento.com.br/quimica/vinho-delevedurado 


\section{INTRODUÇÃO}

Não se sabe ao certo quando surgiu a destilação, porém seu primeiro documento impresso difundido na sociedade sobre a aplicação do mesmo se dá por Brunswig, publicado em 1500, embora existam vários relatos históricos (DEKKER, 1993).

O processo de destilação foi introduzido, na Europa Ocidental, pelos árabes através do norte da África. Na época, a técnica despertou interesse dos alquimistas e dos monges, os alquimistas procuravam operar sobre a matéria de modo a aperfeiçoá-la, imitando o que se acreditava ocorrer na natureza (BELTRAN, 1996). O termo destilação corresponde à separação das substâncias voláteis presentes no vinho, inicialmente transformadas em vapor e depois condensadas (MENEGUZZO et al., 2008).

Segundo Foust (1982), a destilação também denominado fracionamento ou destilação fracionada é a separação constituída baseada nas diferenças de volatilidade. $\mathrm{Na}$ destilação, uma fase vapor entra em contato com a fase líquida, e há transferência de massa do líquido para o vapor e deste para aquele. O líquido está no seu ponto de bolha e o vapor em equilíbrio, no seu ponto de orvalho. O líquido e o vapor possuem, em geral, os mesmos componentes, mas em quantidades relativas diferentes.

Seu efeito final é o aumento da concentração do componente mais volátil no vapor e do componente menos volátil no líquido. A parte líquida da destilação, rica em compostos pesados, é direcionada, ao mesmo tempo que a fase vapor é formada pela destilação, mais rica e leve em leves componentes, encaminha-se para o topo da coluna. Para um contato mais eficiente entre as fases que se separam, a torre pode conter qualquer outro tipo de recheio ou pratos, obstáculos (que servem para ampliar o contato entre as fases, alongando a transferência de massa e calor). Para a eficiência da coluna aumentar, podem ser dispostos no topo e fundo, respectivamente, um condensador e um refervedor (GAUTO, 2011).

RC: 89567

Disponível em: https://www.nucleodoconhecimento.com.br/quimica/vinho-delevedurado 
Segundo Meneguzzo (2008), a mistura água e álcool apresenta ponto de ebulição variável em função do grau alcoólico. Assim, o ponto de ebulição de uma solução hidro alcoólica é intermediário entre aquele da água e do álcool e será tanto mais próximo deste último quanto maior for o grau alcoólico da solução.

Durante muito tempo, esse tem sido um importante método de separação e/ou purificação de compostos químicos em laboratórios e em indústrias, pois além de se tratar de um procedimento simples é eficiente e economicamente viável para muitos processos de separação de misturas (BELTRAN, 1996).

Existem quatro métodos básicos para se efetuar uma separação de líquidos por destilação: Destilação diferencial ou simples; destilação em equilíbrio ou flash; destilação fracionada ou retificação e destilação a vácuo.

De acordo com Gauto (2011) a destilação diferencial ou simples mostrada na Figura 1, é um processo muito usado na purificação de líquidos e consiste basicamente na vaporização de um líquido por aquecimento seguida da condensação do vapor formado. Em uma solução ideal, o ponto de ebulição é representado pela igualdade da pressão atmosférica com a somatória das pressões parciais dos líquidos. Tendo em vista que o vapor é mais rico no componente mais volátil, o líquido original se enfraquece neste, ao passo que a separação ocorre. Como resultado, o vapor produzido se empobrece também no menos volátil e a composição do produto destilado se transforma na medida em que a destilação continua. os destilados e as destilações de laboratório conseguidos de mostos alcoólicos fermentados são amostras deste tipo e destilação.

RC: 89567

Disponível em: https://www.nucleodoconhecimento.com.br/quimica/vinho-delevedurado 
Figura 1: Esquema de uma destilação diferencial.

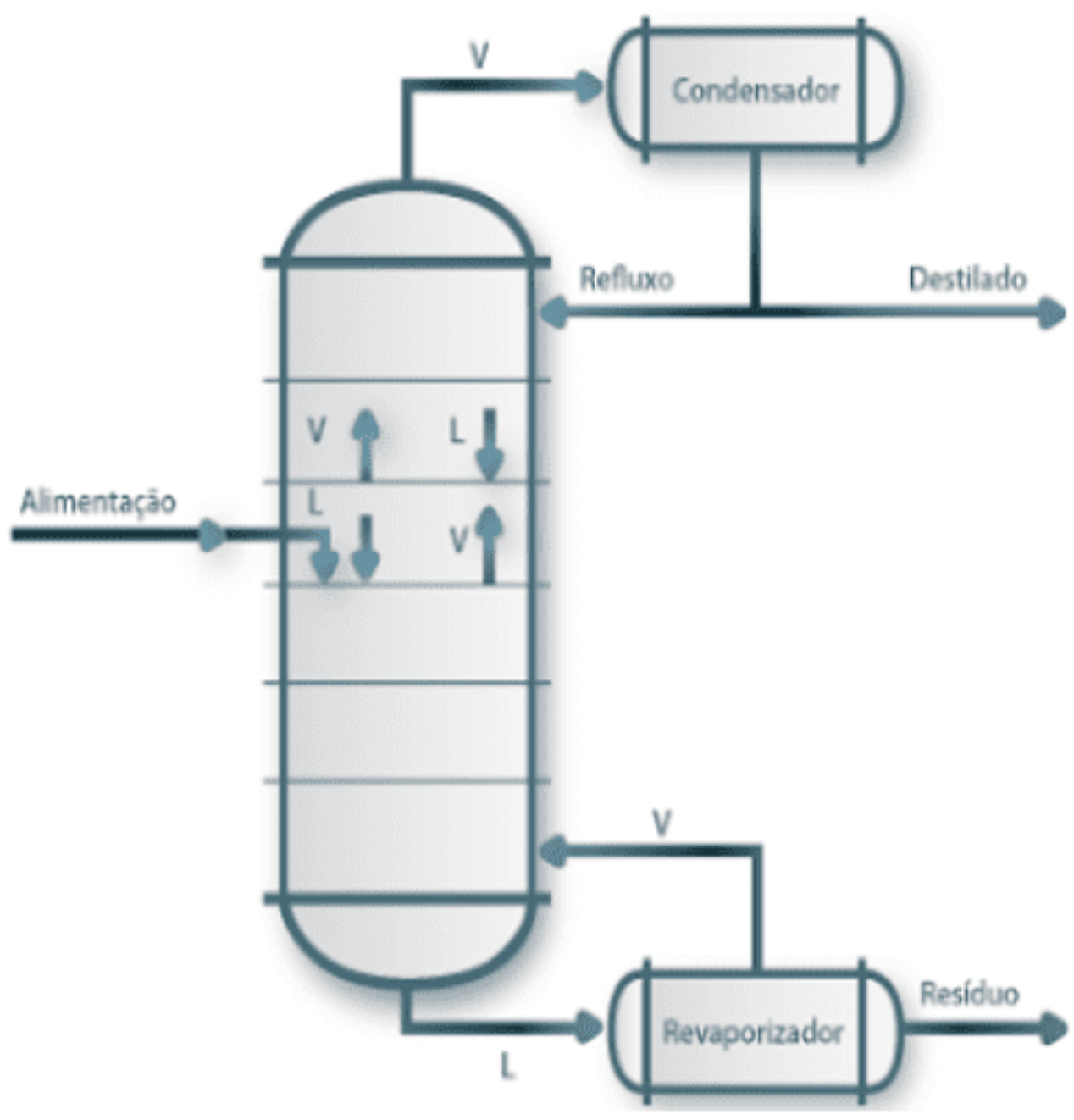

Fonte:

(http://labvirtual.eq.uc.pt/siteJoomla/index.php?option=com_content\&task=view\&id=2 23\&/temid=413). Acesso em: 05 out 2020.

Já a destilação flashconforme Figura 2, é uma destilação de um estágio único, chamada também de destilação de equilíbrio. É conseguida mediante o prévio aquecimento da mistura alimentada e sua passagem sequente por uma válvula que reduz a pressão. A pressão da mistura é levada para um valor menor que sua pressão de vapor naquela temperatura e ocorre a vaporização parcial, separando os componentes da mistura (GAUTO, 2011).

RC: 89567

Disponível em: https://www.nucleodoconhecimento.com.br/quimica/vinho-delevedurado 
Figura 2: Esquema de uma destilação flash.

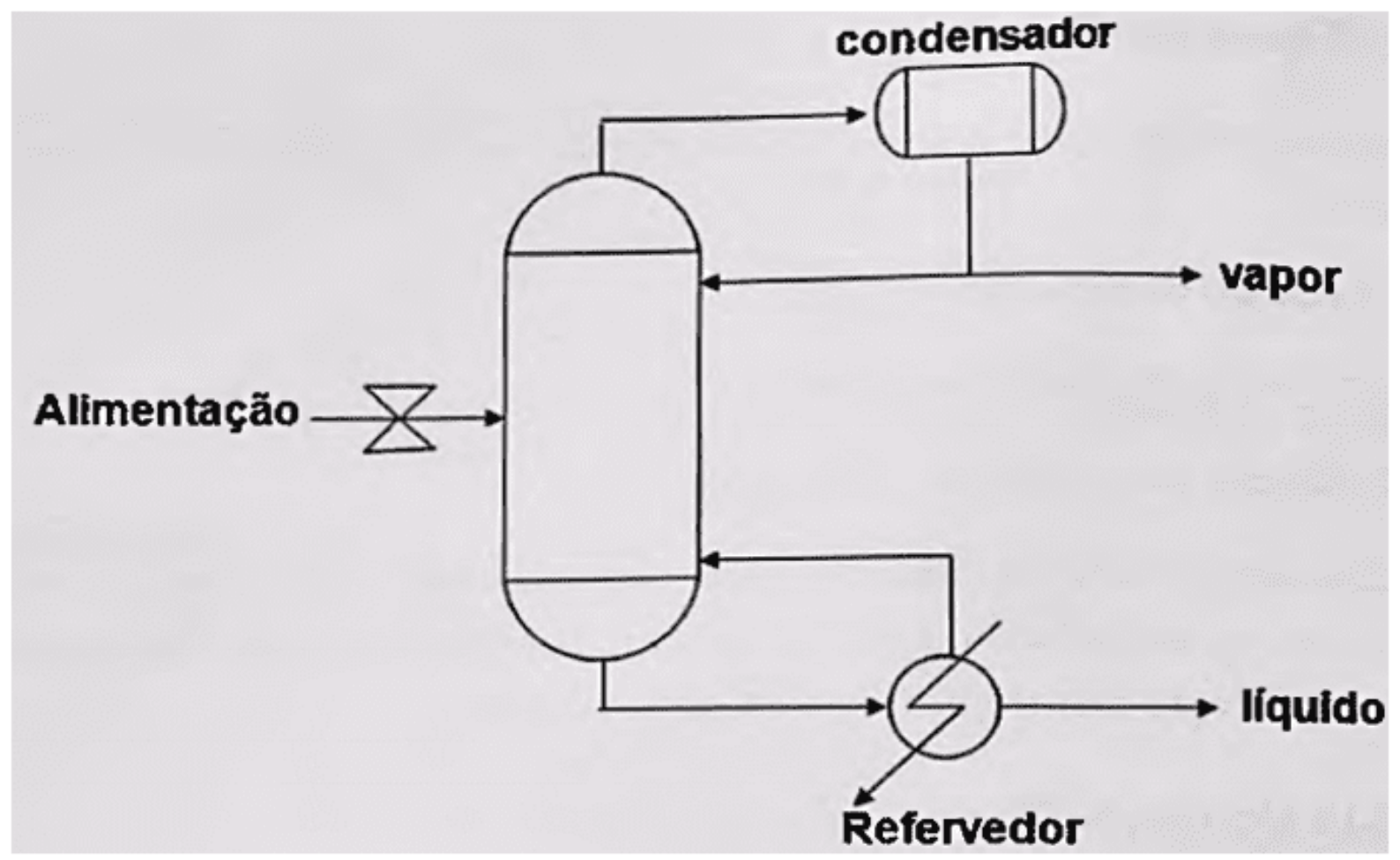

Fonte: (GAUTO, 2011).

$\mathrm{Na}$ destilação simples, as frações iniciais do destilado, ricas no componente mais volátil, se enriquecem com as menos voláteis. Dessa forma, para ter como aumento a eficácia desse seguimento de purificação, o ideal seria destilar constantemente a fração, de uma maneira que se conseguisse apenas o componente mais variável nessas frações iniciais. Para efetuar essas "várias destilações", é utilizado uma coluna de fracionamento, que possibilita em só uma destilação ocasionando uma sequência de estágios de equilíbrio na parte interna da coluna (GAUTO, 2011).

Gauto (2011) aduz que a destilação fracionada é o mais usado industrialmente, por ser mais eficiente e por separar uma mistura multicomponente, da qual várias substâncias podem ser separadas, fazendo-se os cortes no fracionamento da mistura. Os cortes em uma destilação são as frações retiradas em estabelecida altura da 
coluna de destilação, que, por haver temperaturas distintas em cada ponto ao longo do eixo vertical, gera produtos da destilação diferentes em cada um desses pontos.

Na destilação fracionada da Figura 3, a carga é fornecida em um ponto chamado de ponto prato ótimo ou ótimo, encontrado nas vizinhanças do centro da coluna. A carga desce pelos pratos de destilação, que possibilitam o contato entre o seu vapor e líquido. Esse líquido não volatilizado que desce, chega até a área da coluna, onde obrigatoriamente é passada pelo refervedor. Ali, parte da mistura líquida é vaporizada, e os vapores produzidos ascendem pela coluna, em contrapartida com o líquido que desce (GAUTO, 2011).

Figura 3: Esquema de destilação fracionada.

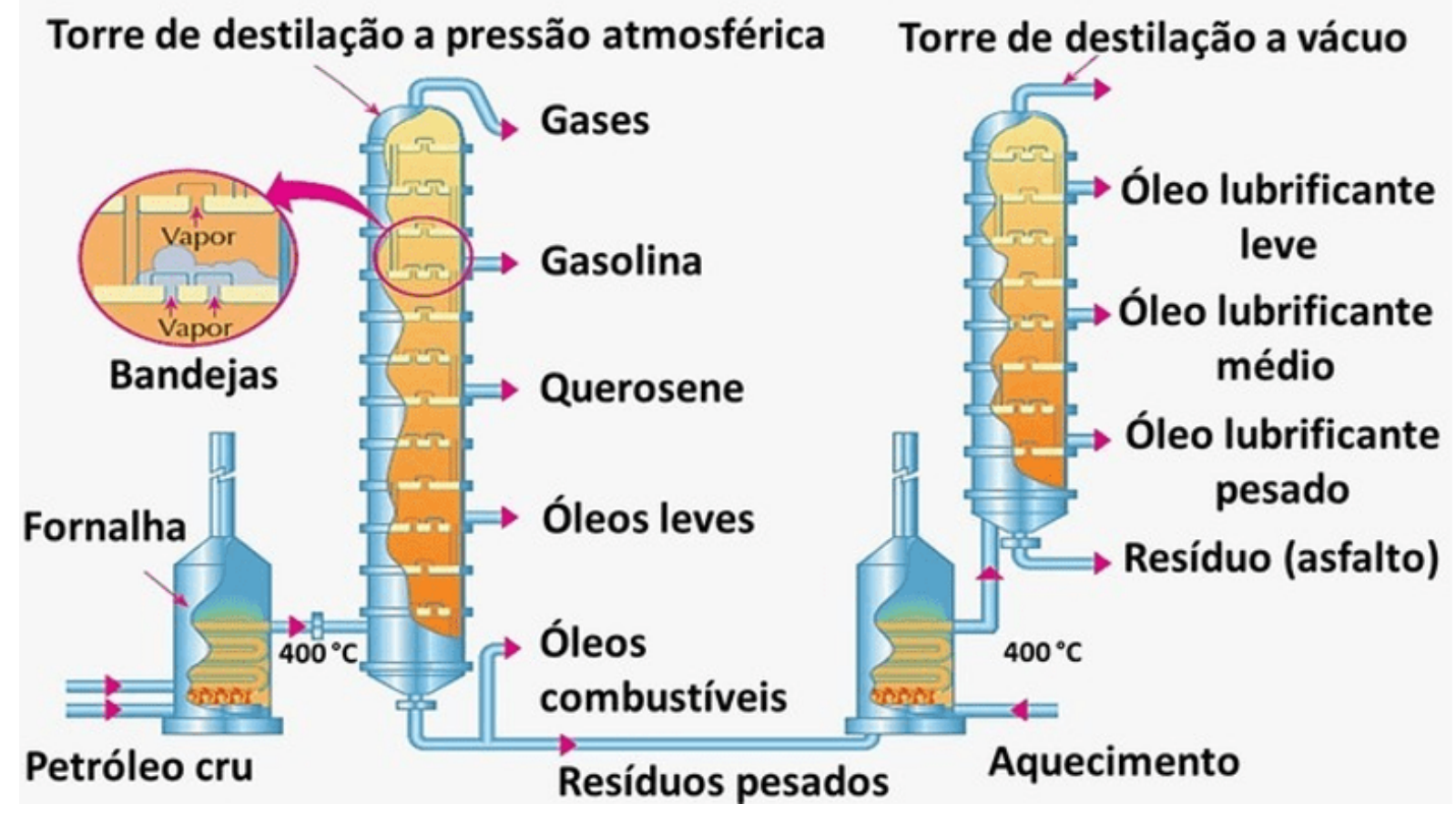

Fonte: (https://www.todamateria.com.br/refino-petroleo/). Acesso em: 05 out 2020.

Para misturas com substâncias de baixa volatilidade e insolúveis em água utiliza-se a destilação por arraste de vapor conforme Figura 4. Nessa operação, os vapores do componente volátil são arrastados pelo vapor de água que está com elevada temperatura. A pressão de vapor do líquido com a pressão de vapor dá água faz com

RC: 89567

Disponível em: https://www.nucleodoconhecimento.com.br/quimica/vinho-delevedurado 
que o líquido entre em ebulição antes de atingir a temperatura de ebulição, conhecida a pressão atmosférica. A destilação por arraste de vapor é utilizada geralmente para a purificação de álcoois de elevada massa molar, de ácidos graxos, frações de petróleo e substâncias que se decompõem a temperaturas próximas da temperatura de ebulição. Após essa operação, alguns processos utilizam a extração líquido-líquido para separar a substância arrastada do seu solvente (MATOS, 2015).

Figura 4: Esquema de uma destilação a vácuo.

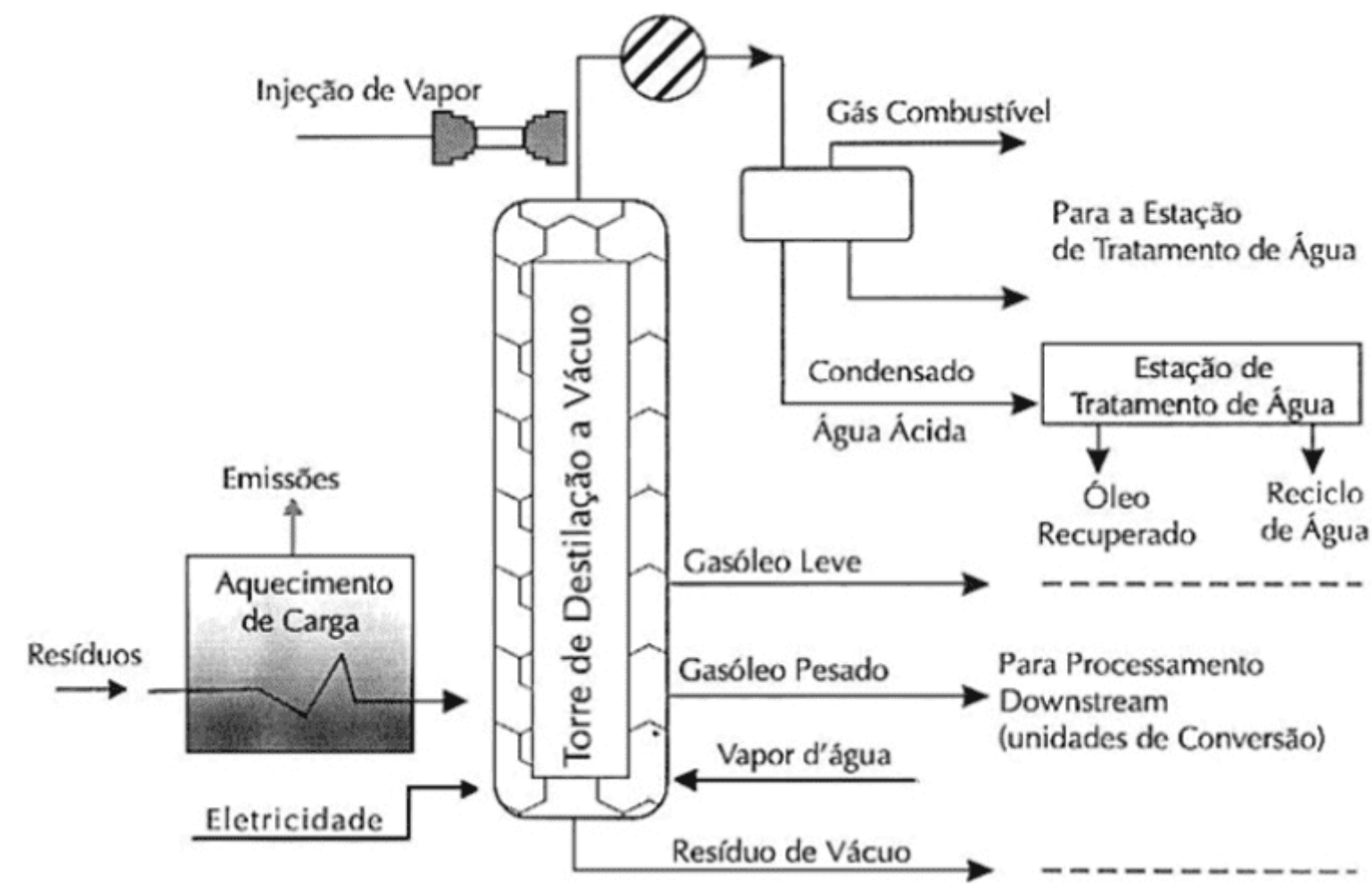

Fonte: (https://slideplayer.com.br/slide/10694560/). Acesso em: 01 mar 2021.

Após o término da fermentação, se separa o fermento do vinho delevedurado através do processo de centrifugação, onde o vinho delevedurado ou centrifugado, será destinado à destilação, onde o álcool é separado, concentrado e purificado e o leite de levedura, fermento, será reciclado no processo para ser reutilizado como um novo pé-de-cuba, após diluição em água e acidificação com ácido sulfúrico (SOUZA, 2003).

RC: 89567

Disponível em: https://www.nucleodoconhecimento.com.br/quimica/vinho-delevedurado 
Tendo em vista a importância do etanol, o mesmo sendo um combustível $25 \%$ menos poluente na atmosfera e atualmente muito utilizado na desinfecção de ambientes e antissepsia de mãos, esse trabalho tem como objetivo desenvolver um destilador simples para vinho delevedurado, visando máxima separação de álcool.

\section{METODOLOGIA}

O presente projeto foi realizado no munícipio de Fernandópolis-SP, sendo baseado no sistema operacional da Usina Alcoeste, situada no Unnamed Road, onde buscouse reproduzir um protótipo, em menor escala, de um destilador simples, utilizado na usina, para separação do álcool do vinho delevedurado. A Figura 5 mostra as etapas do desenvolvimento do protótipo.

Figura 5: Etapas do desenvolvimento do projeto.

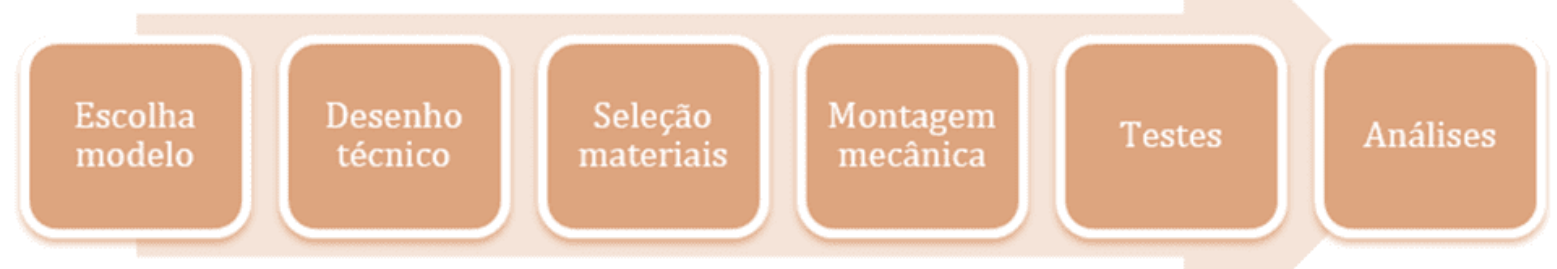

Fonte: Autoria própria.

Para início da confecção do destilador, plotou-se um desenho técnico conforme Figura6 na escala em centímetros.

RC: 89567

Disponível em: https://www.nucleodoconhecimento.com.br/quimica/vinho-delevedurado 
Figura 6: Desenho técnico do destilador.

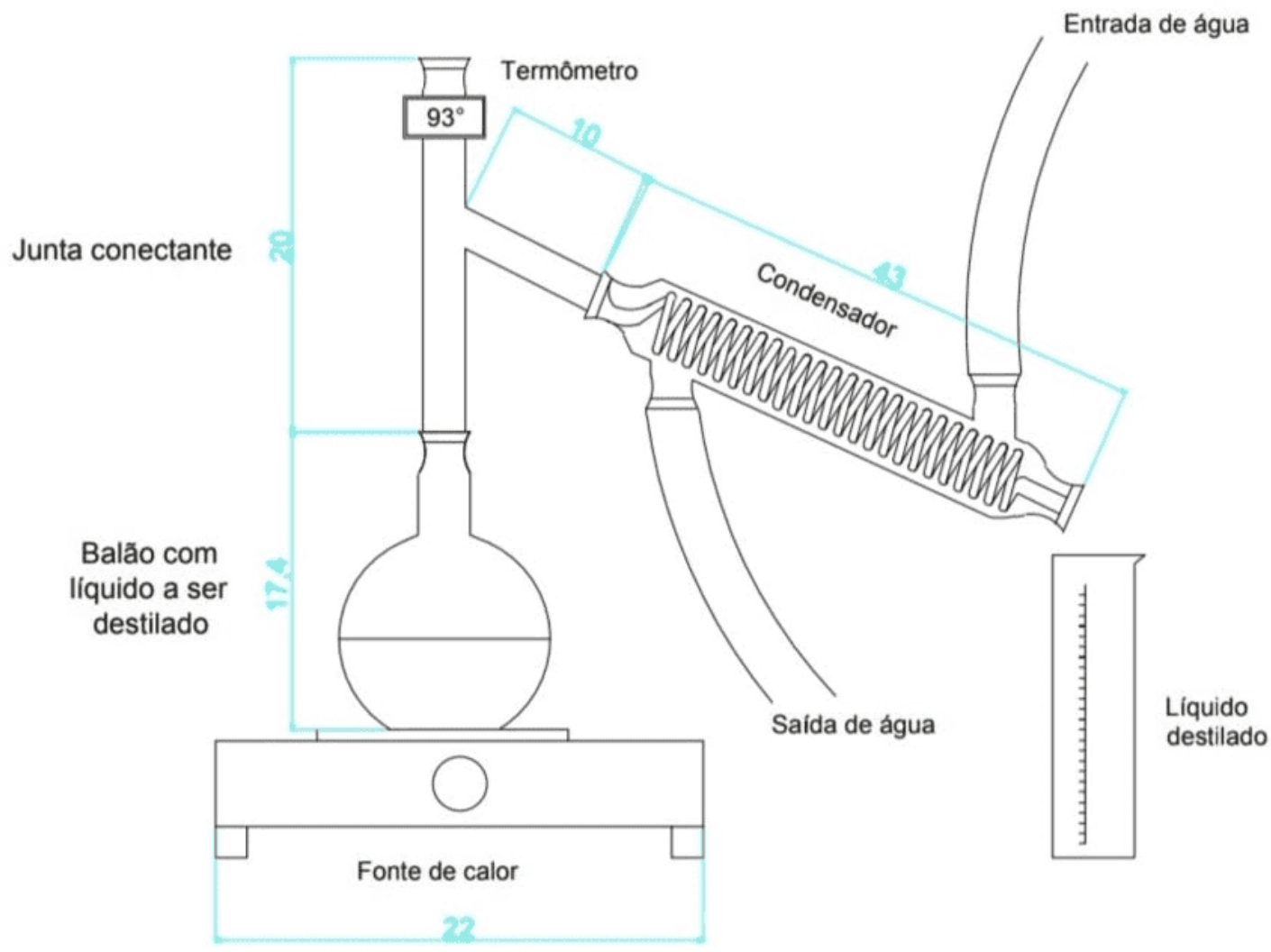

Fonte: Autoria própria.

Os materiais utilizados foram adquiridos através de recursos próprios, conforme Tabela 1.

Tabela 1: Materiais utilizados.

\begin{tabular}{|l|l|l|l|l|}
\hline Material & Quantidade & Unidade & $\begin{array}{l}\text { Valor unitário } \\
(\mathrm{R} \$)\end{array}$ & $\begin{array}{l}\text { Valor Total } \\
(\mathrm{R} \$)\end{array}$ \\
\hline $\begin{array}{l}\text { Balão de vidro fundo } \\
\text { chato }\end{array}$ & 1 & un & 89,00 & 89,00 \\
\hline $\begin{array}{l}\text { Balão volumétrico } \\
\text { Condensador serpentina }\end{array}$ & 1 & un & 26,53 & 26,53 \\
\hline
\end{tabular}

RC: 89567

Disponível em: https://www.nucleodoconhecimento.com.br/quimica/vinho-delevedurado 


\begin{tabular}{|l|l|l|l|l|}
\hline $\begin{array}{l}\text { Junta conectante } \\
\text { adaptadora }\end{array}$ & 1 & un & 60,00 & 60,00 \\
\hline Mangueira & 1 & m & 22,40 & 22,40 \\
\hline Resistencia & 1 & un & 70,00 & 70,00 \\
\hline Rolha de silicone 8 & 1 & un & 8,40 & 8,40 \\
\hline Termômetro & 1 & un & 60,00 & 60,00 \\
\hline Total & & & & $\mathbf{3 8 0 , 3 3}$ \\
\hline
\end{tabular}

Fonte: Autoria própria.

Após a aquisição do balão de fundo chato de $500 \mathrm{ml}$, realizou-se a conexão da junta adaptadora, onde foi colocado a rolha número 8 na parte superior. Para isso, foi realizado um furo com broca $6 \mathrm{~mm}$ na rolha para inserir o termômetro de controle de temperatura.

Depois, acoplou-se ao condensador que está com o fluido frio circulando em sentido oposto ao fluido destilado. Na saída do condensador, instalou-se uma mangueira de $8 \mathrm{~mm}$ de espessura com $10 \mathrm{~cm}$ de comprimento, para conduzir o fluido destilado ao balão volumétrico de $50 \mathrm{ml}$.

Para fornecer a energia térmica ao processo de destilação, utilizou-se uma resistência conectada a energia. Foi realizado o controle manual da temperatura observando o termômetro acoplado ao balão. Figura 6 representa o fluxograma do processo.

RC: 89567

Disponível em: https://www.nucleodoconhecimento.com.br/quimica/vinho-delevedurado 
Figura 6: Realização da montagem.

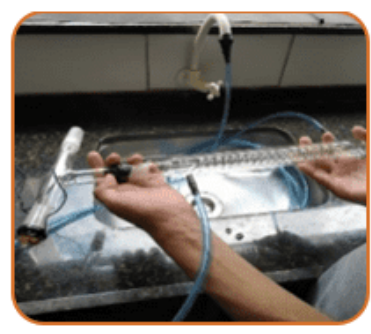

Junção das mangueiras ao condensador e a junta conctante

Fonte: Autoria propria.
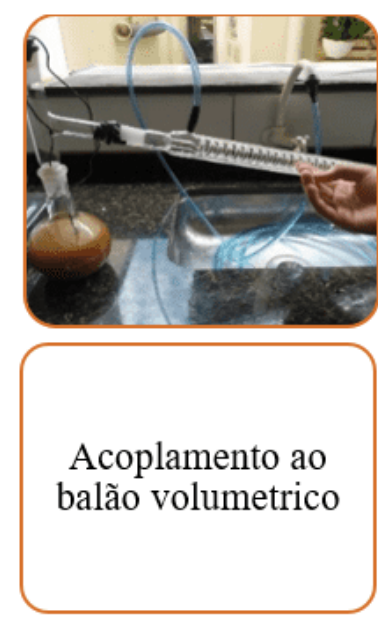
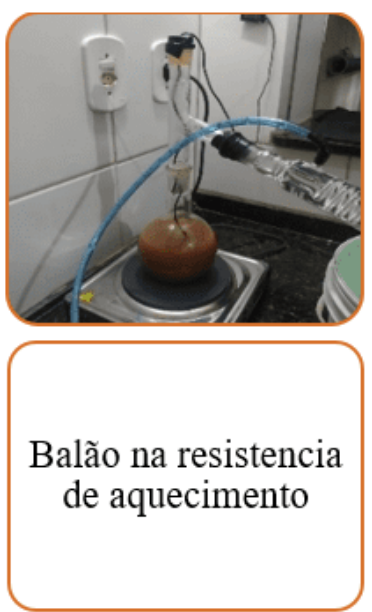

\subsection{TESTES}

Os testes foram realizados na Universidade Brasil, em Fernandópolis- SP, situada em Estrada projetada F1, S/N Fazenda Santa Rita, onde iniciou-se os mesmos com a medição do Grau GL do vinho.

Após essa medição, realizou-se a medição em proveta de $500 \mathrm{ml}$ de vinho onde adicionou-se ao balão de fundo, e ligou-se a resistência a tomada até atingir $93^{\circ} \mathrm{C}$.

Adicionou-se um balde para o condensador atingir a altura ideal da saída do balão. Então ligou-se uma mangueira a torneira e deixou-se a mesma aberta durante o processo para troca térmica do destilado ao fluido frio no condensador.

Conectou-se outra mangueira a saída do condensador. Na saída do condensado foi adicionando um balão volumétrico para a capitação do álcool.

$\mathrm{O}$ processo durou cerca de $2 \mathrm{~h}$ até a evaporação máxima do vinho, desligou-se a resistência. Os demais testes se repetiram da mesma maneira, tendo como objetivo cada teste atingir $100 \mathrm{ml}$ de álcool. Após atingir essa marca, o processo era lavado e reiniciado.

RC: 89567

Disponível em: https://www.nucleodoconhecimento.com.br/quimica/vinho-delevedurado 
A Figura 7 representa o protótipo montado pronto para destilação.

Figura 7: Protótipo concluído.

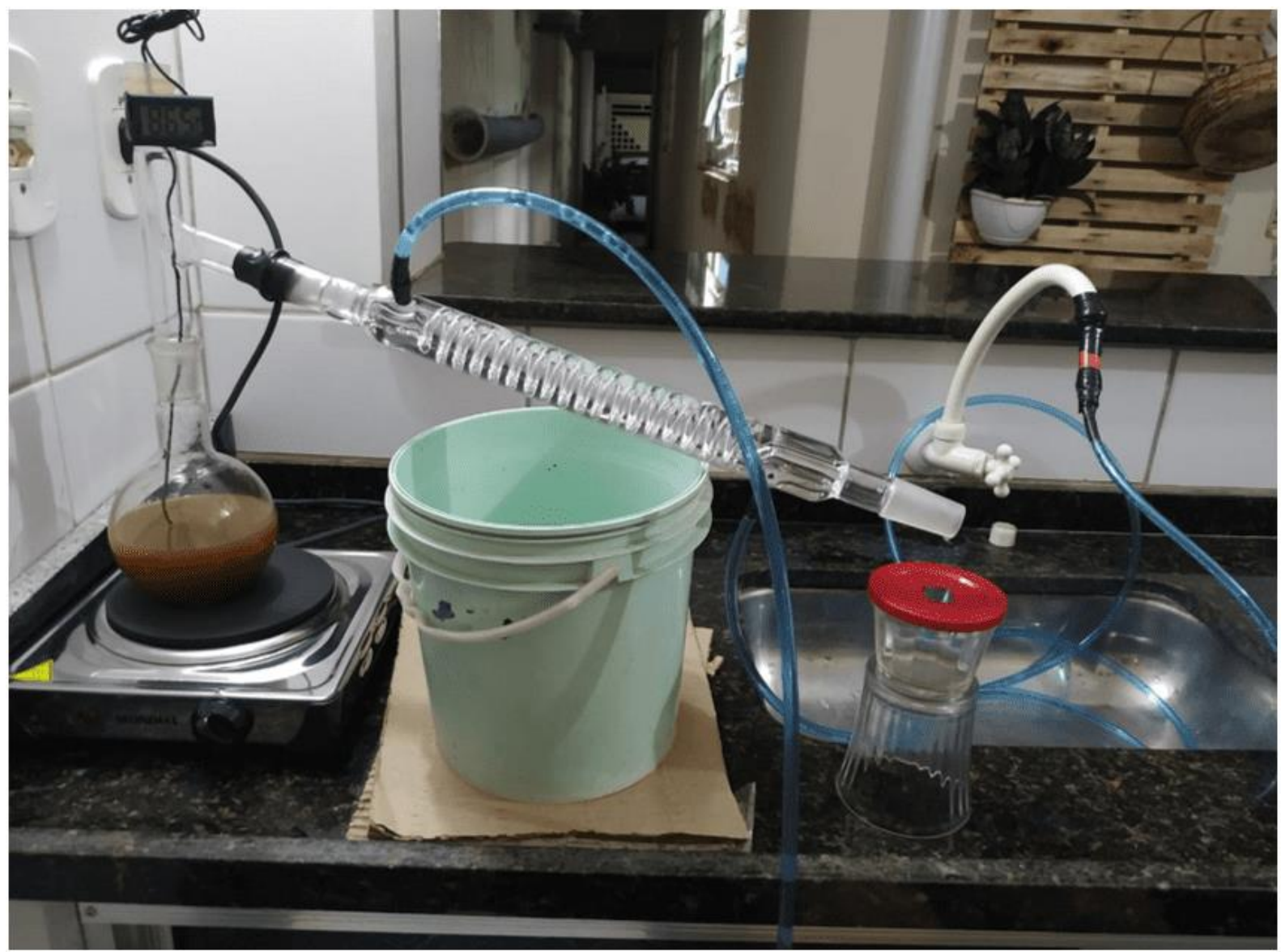

Fonte: Autoria própria.

\subsection{ANÁLISES}

\subsubsection{ANÁLISES DO VINHO DELEVEDURADO}

As análises foram realizadas no local da destilação. Para iniciar-se o processo coletou-se o vinho delevedurado, transportou-se até o local dos testes. Após a chegada do vinho, colocou-se numa proveta de $100 \mathrm{ml}$ previamente lavada com água destilada. Lavou-se o densímetro com água destilada, secou-se com papel macio e adicionou-se a proveta junto ao vinho afim de obter o Grau GL do mesmo.

RC: 89567

Disponível em: https://www.nucleodoconhecimento.com.br/quimica/vinho-delevedurado 


\subsubsection{ANÁLISES DO ÁLCOOL DESTILADO}

As análises foram realizadas no local da realização da destilação. Onde iniciou-se com a lavagem da proveta de $100 \mathrm{ml}$ com água destilada, adicionou-se o álcool destilado. Lavou-se o densímetro com água destilada, secou-se com papel macio e adicionou-se a proveta a fim de obter o Grau GL.

\subsubsection{BALANÇO DE MASSA NO DESTILADOR}

Segundo Felder (2008), o projeto de uma nova análise ou novo processo de um já existente não estão completados até que se disponha que as saídas e entradas do processo inteiro e de cada unidade individual satisfazem as equações de balanço de balanços de material ou massa. A seguir temos duas equações do balanço de massa, sendo a Equação 1 a fórmula do balanço global e a Equação 2, o balanço de massa por componente

$$
F=D+W
$$

(Equação 1)

$$
F \cdot Z^{A}=D \cdot X_{D}^{A}+W \cdot X_{W}^{A}
$$

(Equação 2)

Onde;

F: Carga/alimentação.

D: Destilado.

W: Produto de fundo.

$Z^{A}$ : Fração do componente.

RC: 89567

Disponível em: https://www.nucleodoconhecimento.com.br/quimica/vinho-delevedurado 
$\mathrm{X}_{\mathrm{D}}^{\mathrm{A}}$

: Fração do componente do destilado A.

$\mathrm{X}_{\mathrm{W}}^{\mathrm{A}}$ : Fração do composto, produto de fundo.

\section{RESULTADO E DISCUSSÃO}

Os destiladores como já descritos tem a finalidade e separação de misturas, sejam elas simples ou compostas através da sua volatilidade, este processo é muito usado em usinas, petrolíferas e laboratórios. O vinho delevedurado que adquirimos para o teste de destilação variou o ${ }^{\circ} \mathrm{GL}$ de 4,6 a 4,4. Segundo Santos (2017) o vinho ideal para destilação varia de $7^{\circ}$ a $10^{\circ} \mathrm{GL}$. O protótipo apresentou $64^{\circ} \mathrm{GL}$ a uma temperatura de $27^{\circ} \mathrm{C}$, sendo que o equipamento da literatura faz parte de uma destilação múltipla, enquanto o protótipo pertence a uma destilação simples.

A Figura 8 apresenta um gráfico, onde é possível fazer uma análise melhor dos resultados entre o protótipo pertence que foi construído e o material que utilizamos como literatura, pode-se notar que o valor não é muito distante.

RC: 89567

Disponível em: https://www.nucleodoconhecimento.com.br/quimica/vinho-delevedurado 
Figura 8:Testes do destilador.

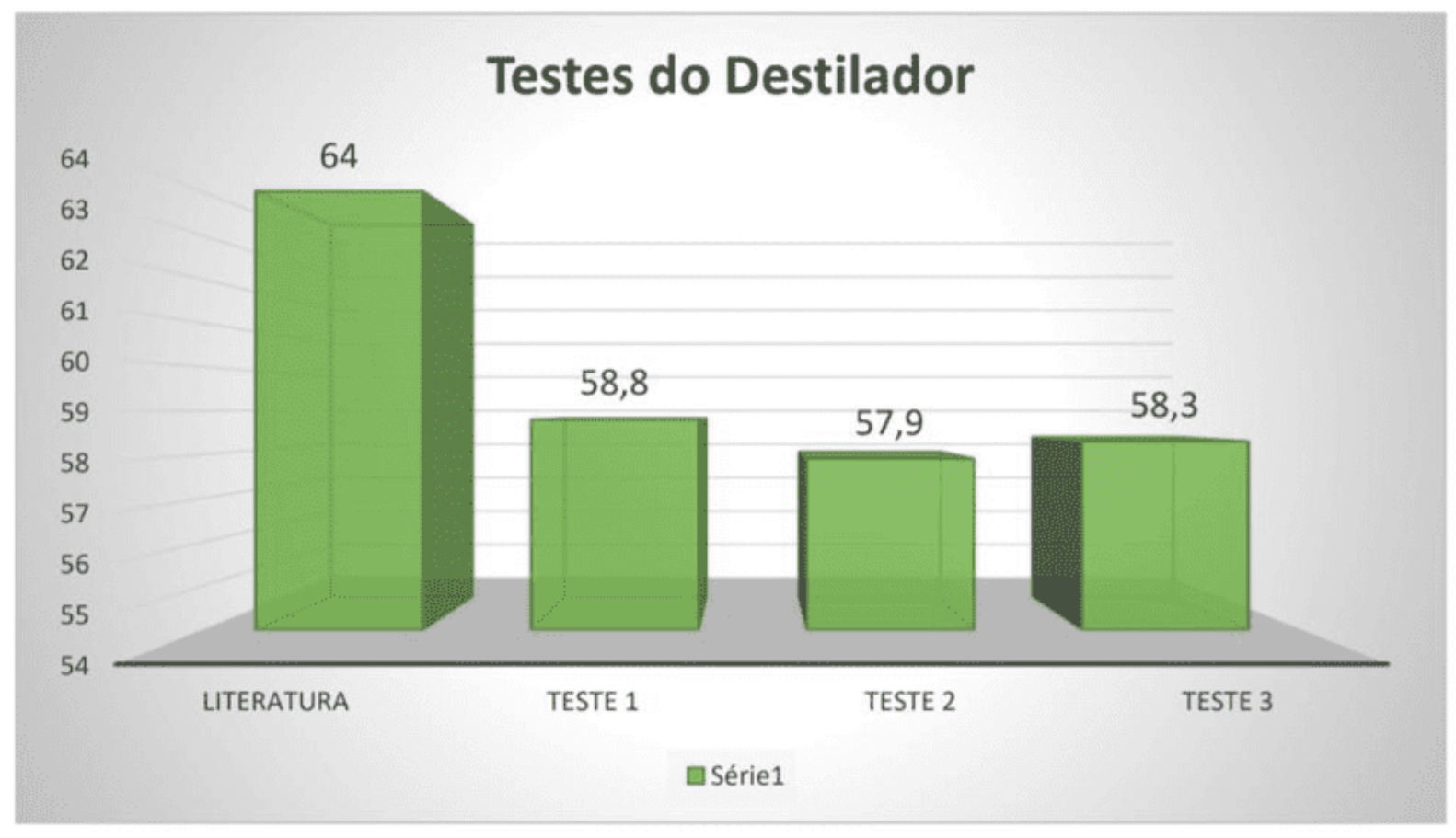

Fonte: Autoria própria.

Como já dito as equações 1 e 2 representaram o balanço de massa global e por componente. Segundo Oliveira et al. (2016), o valor obtido do balanço de massa após a destilação é $87500 \mathrm{ml} / \mathrm{h}$ ou como descrito no artigo $2100 \mathrm{~L} / \mathrm{dia}$, porém o protótipo obteve os seguintes resultados: balanço global de $469,3 \mathrm{ml} / \mathrm{h}$ e o balanço por componente foi de $30,70 \mathrm{ml} / \mathrm{h}$. Esses valores são muito importantes, pois são a partir deles que temos um monitoramento do fluxo de massa e podemos também compreender se o produto está sendo produtivo ou não.

\section{CONCLUSÃO}

Esse trabalho visou demonstrar o funcionamento de uma destilação simples para obter a máxima separação dos componentes e com os resultados apresentados podese concluir que o mesmo foi eficiente e atingiu os objetivos. Apesar do vinho delevedurado estar com pouco GL devido as chuvas e a parada na fermentação, 
obteve-se ótimos resultados. Pode-se concluir também que se o GL estivesse nas condições ideais seu desempenho teria sido maior.

\section{REFERÊNCIAS}

CANTO, E. L.; "Química na Abordagem do cotidiano". 1ª Edição, Editora saraiva, 2016.

DEKKER, M. "Unit operationshandbook". 11르 ed. Austin Texas: John J. Mcketta, 1993.

FELDER, R. M.; ROUSSEAU, R.W. "Princípios elementares dos processos químicos". $3^{\mathrm{a}}$ ed. LTC, 2008.

FOUST, A.S.; WENZEL, L.A.; CLUMP, C.W.; MAUS, L.; ANDERSEN, L.B. “Princípios das Operações Unitárias” 2ª . Edição, Guanabara Dois, 1982.

GAUTO, M.; Rosa, R. G.; "Processos e Operações Unitárias da Indústria Química”, 1a. Edição, Ciência Moderna, 2011.

MATOS, Simone P. Operações Unitárias - Fundamentos, Transformações e Aplicações dos Fenômenos Físicos e Químicos. Editora Saraiva, 2015. <https://integrada.minhabiblioteca.com.br/\#/books/9788536520018/cfi/123!/4/4@0.00 :37.9>. Acesso em: 16 de Out de 2020.

OLIVEIRA, B. L., COSTA, R. S., JUNIOR, S. K., BERGAMACHI, T. "Projeto produção de cachaça industrial". 2016. Disponível em: $<$ https://www.google.com/url?sa=t\&source=web\&rct=j\&url=http://www.ceepcuritiba.co m.br/wp-content/uploads/2019/05/Projeto-producao-decachacaindustrial.pdf\&ved=2ahUKEwjc_rHEzYXtAhUIJ7kGHUD8BUEQFjAAegQIAh AB\&usg=AOvVaw3hVQxqjGlgaq9L4h6So6am\&cshid=1605479615792 $>$. Acesso em: 15 de Nov. de 2020.

RC: 89567

Disponível em: https://www.nucleodoconhecimento.com.br/quimica/vinho-delevedurado 
RIZZON, L. A.; Meneguzzo, J.; "Sistema de Produção de Destilado de Vinho", 2008.

<https:/sistemasdeproducao.cnptia.embrapa.br/FontesHTML/Vinho/SistemaProduca oDestiladoVinho/destilacao.htm>. Acesso em 04 de outubro de 2020.

SANTOS, F. A. "Cálculo da eficiência de coluna de destilação na fabricação de etanol"; 2017; Disponível em:<https://repositorio.uniube.br/bitstream/123456789/431/1/TCC\%20\%20Felipe\%2 0Alves\%20dos\%20Santos.pdf>. Acesso em 08 de Nov. de 2020.

SOUZA, C. A. M.; MUTTON. R. J. M. Floculação de leveduras por Lactobacillusfermentum em processos industriais de fermentação alcoolica avaliada por técnica fotométrica; 2003; Disponível em: $<$ https://www.scielo.br/pdf/cagro/v28n4/23.pdf>. Acesso em: 16 de Out.de 2020.

Enviado: Março, 2021.

Aprovado: Junho, 2021. 